\title{
Editorial
}

\section{Salir de armario o salir del estadio, ¿esa es la cuestión?}

\section{Joaquín Piedra}

¿Por qué en nuestro país cuesta tanto encontrar a un deportista profesional, de renombre, que 'salga del armario'? A nivel social existen grandes diferencias entre la situación en los años 70, 80 o 90, y la actual para un deportista LGTBI. A nivel legislativo, en general, encuentran amparo y protección de la justicia. A nivel de medios de comunicación, encontramos gran cantidad de personajes de diversas orientaciones e identidades en nuestras pantallas. Contamos además con un extenso tejido asociativo que defiende y lucha por sus derechos ¿es el contexto deportivo diferente al resto de espacios de la vida diaria?

En los últimos años han salido a la luz pública diversos atletas como Mapi León, Víctor Gutiérrez, Marta Mangué, Laura Nicholls, Javier Raya..., ejemplos de grandes deportistas, que visibilizan al colectivo LGTBI y traen a la actualidad mediática el debate sobre diversidad sexual y deporte. Aunque cada situación y cada experiencia es personal e individual, la realidad es que el entorno deportivo (especialmente masculino) no facilita la aceptación inicial de la orientación sexual (Vilanova, Soler, y Anderson, 2018). Aunque afortunadamente no todos relatan malas experiencias, lo habitual es haber vivenciado $u$ observado situaciones de discriminación y acoso (PérezSamaniego, Fuentes-Miguel, Pereira-García, López-Cañada, y Devís-Devís, 2019; Piedra, 2015). Este último verano, en la muy avanzada y desarrollada Francia, se han sucedido situaciones de homofobia en los campos de fútbol (Barbero, 2019). Sucesos que ya se había repetido antes en otros países occidentales como Reino Unido (Syed, 2018), Dinamarca (Kelleher, 2019) o España (Rioja, 2016).

Frente a este panorama, es comprensible que los niños y los jóvenes atletas LGTBI se debatan entre 'salir del armario' y recibir críticas, insultos o miradas dentro y fuera del equipo, forzando a abandonar la práctica deportiva en algunos casos; o mantenerlo en privado y seguir su práctica deportiva con "normalidad" en la cultura deportiva del Don't ask, don't tell (Anderson, 2011). Yo me pregunto ¿por qué deben elegir? ¿por qué no pueden hablar abiertamente de su sexualidad y seguir compitiendo como el resto de sus compañeros y compañeras?

Para que en el futuro nuestros niños y niñas no tengan que plantearse esta cuestión se nos abren dos caminos, uno a corto y otro a largo plazo. Para recorrer el camino corto hará falta que nuevos deportistas mediáticos 'salgan del armario', contando con el apoyo de sus compañeros y compañeras, entrenadores, gestores deportivos y responsables institucionales. Que los niños y niñas cuenten con referentes a imitar les animará a seguir en la práctica 
deportiva. Para acometer el camino largo tendremos que implicar a la educación, especialmente a la educación física, como único camino para "apuntalar" los avances de los últimos años. Revolucionar la formación en educación física se hace imprescindible para captar el interés hasta ahora inexistente de los docentes e investigadores de la educación física (Barbero, 2003). Como ya señalábamos (Piedra, Ramírez-Macías, y Latorre, 2014), contar con un profesorado de educación física bien formado en la igualdad de género, sensible a las discriminaciones, e implicado en la búsqueda de soluciones, permitirá que este camino sea menos cuesta arriba que en la actualidad.

\author{
Dr. Joaquín Piedra
} Universidad de Sevilla

\title{
REFERENCIAS BIBLIOGRÁFICAS
}

Anderson, E. (2011). Updating the Outcome. Gay athletes, straight teams, and coming out in educationally based sport teams. Gender \& Society, 25(2), 250-268. https://doi.org/10.1177/0891243210396872

Barbero, A. R. (14 de septiembre de 2019). Por racismo sí, pero por homofobia no: la "sensibilidad selectiva" del fútbol. Marca. Recuperado de https://bit.ly/3213hmw

Barbero, J. I. (2003). La educación física y el deporte como dispositivos normalizadores de la heterosexualidad. En Ó. Guasch y O. Viñuales (Eds.), Sexualidades: diversidad y control social (pp. 355-377). Barcelona: Bellaterra.

Kelleher, P. (10 de abril de 2019). Danish footballer Viktor Fischer slams fans for chanting gay slurs. Pink News. Recuperado de https://www.pinknews.co.uk/2019/04/10/viktor-fischer-football-homophobia/

Pérez-Samaniego, V., Fuentes-Miguel, J., Pereira-García, S., López-Cañada, E., y Devís-Devís, J. (2019). Experiences of trans persons in physical activity and sport: A qualitative meta-synthesis. Sport Management Review, 22(4), 439-451. https://doi.org/10.1016/..smr.2018.08.002

Piedra, J. (2015). Gays y lesbianas en el deporte: discurso de jóvenes universitarios españoles en torno a su aceptación. Movimiento, 21(4), 1067-1081.

Piedra, J., Ramírez-Macías, G., y Latorre, Á. (2014). Visibilizando lo invisible: creencias del profesorado de educación física sobre homofobia y masculinidades. Retos, 25, 60-66.

Rioja, R. (21 de noviembre de 2016). ¿Por qué Koke llama "maricón" a Cristiano Ronaldo y las críticas (y mofas) son para el portugués? 20 Minutos. Recuperado de https://bit.ly/2N1jvYF

Syed, M. (7 de septiembre de 2018). Héctor Bellerín: Act differently and it makes you a target - it's dangerous. The Times. Recuperado de https://bit.ly/2q9WkCo

Vilanova, A., Soler, S., y Anderson, E. (2018). Examining the experiences of the first openly gay male team sport athlete in Spain. International Review for the Sociology of Sport. Publicación anticipada en línea. https://doi.org/10.1177/1012690218780860 